Proceedings of the 50th Hawaii International Conference on System Sciences | 2017

\title{
Membership Free Shipping Programs: Effect on Competition and Optimality of Member Fees
}

\author{
Zhong Wen \\ School of Economics and Management \\ Tsinghua University \\ Beijing, China 100084 \\ Email: wenzh@sem.tsinghua.edu.cn
}

\author{
Lihui Lin \\ School of Economics and Management \\ Tsinghua University \\ Beijing, China 100084 \\ Email: linlh@sem.tsinghua.edu.cn
}

\begin{abstract}
Fee-based membership free shipping is an important shipping fee schedule in E-Commerce. This paper studies how the membership free shipping (MFS) program affects firm competition and how to set the membership fee optimally. We find MFS relaxes price competition. The firm that adopts MFS has a higher pricing band than the other firm. Both firms have positive profits, strictly better than when membership free shipping is not a choice. The MFS firm subsidizes subscribers, so the subscribers always have a lower average total cost (price plus shipping fee) per order. The MFS firm could still earn a higher profit than the other firm, although the MFS firm's profit excluding membership fee is lower than that of the other firm. The paper also characterizes how to set the optimal membership fee and shows that an intermediate percentage of subscribers is optimal for the firm that adopts the free shipping program.
\end{abstract}

\section{Introduction}

Shipping charges are an important element in ECommerce. Due to the razor-thin margin of e-tailing, shipping charges often become the make-or-break factor of an ebusiness. E-commerce companies have been using a variety of shipping fee schedules, such as free shipping, flat rate per order, or free shipping when orders are above a given threshold. In recent years, the e-commerce industry has seen a growing interest with membership free shipping (MFS). Consumers who subscribe to MFS need to prepay an annual membership fee, and enjoy free shipping for any order of most product categories, along with other benefits, such as free return ship, and cash back. Amazon Prime is the world's largest MFS program, which charges a $\$ 99$ annual fee and provides its subscribers a free two-day shipping over selected Prime items. According to a survey conducted in late 2015, Amazon may have up to 50 million U.S. Prime subscribers.

Though MFS is thought as a loyalty program to keep consumers. Its cost is rather high. Since consumers selfselect to subscribe to MFS, consumers who shop more are more willing to adopt MFS. Thus MFS providers heavily subsidize their customers. It is estimated that Amazon lost at least $\$ 11$ for each subscriber (Tuttle (2011)). In the fourth quarter of 2015, Amazon's overall shipping costs shot up to $\$ 1.8$ billion, at a speed far out-pacing its revenue growth (Rubin (2016)).

Some argue for MFS on other grounds. Rogowsky (2014) reports that Amazon Prime changes the way people shop and makes Amazon the default shopping destination of its subscribers. Lewis (2006) and Lewis, Singh, and Fay (2006) find free-shipping increases retention rate, greatly increases order incidence rates but leads to smaller order amounts. However they also find the lost revenues from shipping may make firms unprofitable. Tan, Ho, and Tan (2015) compares MFS with contingent free shipping, a traditional shipping schedule in which consumers are eligible for free shipping when the order size reaches a threshold. They model shipping schedules as bundled services and are sources of horizontal product differentiation. By providing a higher value to consumers, retailers gain more profit.

This paper intends to show that despite its high cost and besides aforementioned benefits, MFS relaxes competition and makes all firms better off. This paper also answers questions like what is the optimal membership fee and what is the percentage of subscribers.

We model a duopoly with one firm being the pioneer who adopts MFS. Consumers differ in number of orders per year. The firms would play a Bertrand pricing game and earn zero profit when MFS is unavailable. With MFS, the duopoly will charge different pricing strategies, with the firm with MFS having a higher pricing band than the other firm. Both firms have positive profits. The MFS firm subsidizes the subscribers, so the subscribers always have a lower average total cost (price plus shipping fee) per order. Nevertheless, it still earns a higher profit than the other one. We characterize how to set the optimal membership fee and show that an intermediate percentage of subscribers is optimal for the MFS firm.

This paper contributes to the emerging research on MFS and is related to quantity discount and loyalty program literature. Quantity discount is a widely studied nonlinear price schedule and is a mechanism to achieve price discrimination 
against certain consumers or to influence buyers' ordering pattern (Buchanen (1953), Dolan (1987)). There is a key difference between this paper and a typical quantity discount setting. In the setting of this paper, subscribers (consumers who have higher number of orders per year) do have a lower average shipping cost per order, but offering MFS is always suboptimal for a monopolist, thus never used, while quantity discount is frequently used for monpolistic price discrimination. MFS improves profit only in a competitive setting. Besides, subscribers are not obliged to purchase from the MFS firm, and they may switch to the other firm if it offers a lower total cost. Also in this paper, buyers' ordering pattern is unchanged because of MFS.

Most of the existing research on loyalty programs emphasizes free programs and post-enrollment outcomes. There are few research on fee-based loyalty programs. Ashley, Gillespie, and Noble (2015) studies how loyalty program fees change consumer perceptions and how the loyalty program structure interacts with loyalty program fees to affect customer engagement. This paper contributes to this line research by providing a theoretical framework studying the interaction between fee setting and other important marketing variable, i.e, pricing, and how the program might affect firm competition.

\section{Model}

We consider two firms selling the same products. This paper discusses the case that only one firm offers MFS program, which captures the reality that only a few etailers offer MFS. We will leave the case both firms offering MFS to future study. Firm 1 is the pioneer that provides an MFS program for consumers to enroll in. The MFS program's annual membership fee is $k$. Subscribers of the program can enjoy free shipping for a year. Firm 1 affords the shipping cost for MFS subscribers. Both firms also offer the standard shipping charge policy: a fixed shipping fee $f$ per order. We assume firms do not make money on shipping. The shipping fee, $f$ is used exactly to cover the shipping cost, which is also $f$. Note a MFS subscriber can still buy from firm 2 if it yields higher surplus for her. The product cost is normalized to zero.

The total consumer population is normalized to 1 . We assume consumers differ in the number of orders per year, which is represented by variable $x$ and $x$ is a random variable associated with p.d.f. $g(x)$ and c.d.f. $G(x), x, x \in$ $(0, \bar{x})$. This consumer heterogeneity is a prerequisite for an MFS program: if all consumers have an equal number of orders per year, the MFS membership fee will be the total shipping fees in a year and all consumers will be indifferent between joining the program or not. Lewis (2006) and Lewis et al. (2006) empirically test how free-shipping programs affect order basket size. This effect is not the focus of this paper. So we assume each consumer only buys one product per order. We assume consumers' willingness to pay is sufficiently high, so it will not restrict retailers' pricing.

The game plays out in the following sequence:

1) firm 1 set the MFS membership fee $k$;
2) having observed $k$, consumers decide whether to join the free-shipping program;

3) firms set prices $p_{i}, i=1,2$ simultaneously and independently;

4) having observed both prices, consumers choose between two firms.

We shall solve the game using backward induction.

\section{Analysis}

\subsection{Stage 4: consumer choice}

Consumers choose the firm that gives them higher surplus. There are two types of consumers: MFS subscribers and non-subscribers. For a subscriber, $k$ is a sunken cost. She will buy from retailer 1 if $p_{1}<p_{2}+f$, and from firm 2 if $p_{1}>p_{2}+f$, and from either retailer with equal chance if $p_{1}=p_{2}+f$.

A non-subscriber needs to pay shipping cost $f$ to either firm. So she will buy from the firm with a lower price and from either one with equal chance if prices are equal.

\subsection{Stage 3: pricing strategies}

Clearly consumers with higher $x$ enjoy greater saving from shipping charges. Assume $x^{*}$ is the marginal consumer that is indifferent between subscribe MFS or not. Then consumer $x, x>x^{*}$, must prefer to subscribe the MFS and consumer $x, x<x^{*}$ must prefer not to subscribe. Therefore the number of subscribers is $1-G\left(x^{*}\right)$ and that of the nonsubscribers is $G\left(x^{*}\right)$.

Denote the total orders made by non-subscribers by $a, a=\int_{0}^{x^{*}} t g(t) d t$. Denote the total orders made by all consumers by $b, b=\int_{0}^{\bar{x}} t g(t) d t$. Assume the consumers only purchase one unit product per order. $a$ and $b-a$ are the total units made by non-subscribers and subscribers respectively.

The firms' objective is to find their profit-maximizing pricing strategies. It is obvious that the pricing game does not have a pure-strategy equilibrium. We now turn to characterize a mixed-strategy pricing equilibrium.

Assume the pricing strategy of firm $i$ is characterized by a cumulative distribution $F_{i}(x)$. We can prove that $F_{i}(x)$ is continuous and atomless, the length of the support of $F_{i}$ is $f$, and the supports of $F_{1}(x)$ and $F_{2}(x)$ have an non-empty overlap ${ }^{1}$.

So given strategy $F_{2}(p)$, if retailer 1 sets price at $p$,

- $\quad$ with probability $F_{2}(p)-F_{2}(p-f)$, the subscribers purchase from retailer 1 and non-subscribers purchase from retailer 2 ;

- $\quad$ with probability $1-F_{2}(p)$ : all consumers purchase from retailer 1 ;

- with probability $F_{2}(p-f)$ : all consumers purchase from retailer 2 .

1. The proof is omitted here, which is similar to the one in Jing and Wen (2008). 
Firm 1 receives membership fee $k\left(1-G\left(x^{*}\right)\right)$ from subscribers. Taking consideration of above probabilistic events, firm 1 receives profit $(p-f)(b-a)$ from subscribers with probability $F_{2}(p)-F_{2}(p-f)+1-F_{2}(p)=1-F_{2}(p-f)$ and profit $p a$ from non-subscribers with probability $1-F_{2}(p)$. Therefore Firm 1's expected profit from charging price $p$ is:

$$
\begin{aligned}
\Pi_{1}(p)= & (p-f)(b-a)\left(1-F_{2}(p-f)\right)+ \\
& p a\left(1-F_{2}(p)\right)+k\left(1-G\left(x^{*}\right)\right) .
\end{aligned}
$$

Given strategy $F_{1}(p)$, if retailer 2 sets price at $p$,

- with probability $F_{1}(p+f)-F_{1}(p)$, the subscribers purchase from retailer 1 and non-subscribers purchase from retailer 2 ;

- with probability $1-F_{1}(p+f)$ : all consumers purchase from retailer 2 ;

- with probability $F_{1}(p)$ : all consumers purchase from retailer 1.

Taking consideration of above probabilistic events, firm 2 receives profit $p a$ from only non-subscribers of firm 1 with probability $F_{1}(p+f)-F_{1}(p)$ and profit $p b$ from all consumers with probability $1-F_{1}(p+f)$. Therefore firm 2's expected profit from charging price $p$ is:

$$
\Pi_{2}(p)=p a\left(F_{1}(p+f)-F_{1}(p)\right)+p b\left(1-F_{1}(p+f)\right) .
$$

Denote firm $i$ 's equilibrium strategy by $F_{i}^{*}(p)$ and the equilibrium profit by $\pi_{i}$. Firm $i$ achieves $\pi_{i}$ when it charges a price $p$ in its support, given its opponent charges strategy $F_{j}^{*}(p), j \neq i$, that is $\Pi_{i}\left(p ; F_{j}^{*}(p)\right)=\pi_{i}$.

By the equilibrium condition, we derive the equilibrium strategy as follows.

Proposition 1. There is a unique mixed-strategy equilibrium:

$$
\begin{aligned}
& F_{1}^{*}(p)= \begin{cases}1-\frac{\pi_{2}}{a p} & \frac{\pi_{2}}{a} \leq p<\frac{\pi_{1}-k\left(1-G\left(x^{*}\right)\right)}{b-a}+f \\
\frac{1}{b-a}\left[b-\frac{\pi_{2}}{p-f}\right] & \frac{\pi_{1}-k\left(1-G\left(x^{*}\right)\right)}{b-a}+f \leq p \leq \frac{\pi_{2}}{a}\end{cases} \\
& F_{2}^{*}(p)=\left\{\begin{array}{l}
1-\frac{\pi_{1}-k\left(1-G\left(x^{*}\right)\right)}{(b-a) p} \\
, \frac{\pi_{1}-k\left(1-G\left(x^{*}\right)\right)}{b-a} \leq p<\frac{\pi_{2}}{a} \\
\frac{1}{a}\left[b-\frac{\pi_{1}-k\left(1-G\left(x^{*}\right)\right)+f(b-a)}{p}\right] \\
, \frac{\pi_{2}}{a} \leq p \leq \frac{\pi_{1}-k\left(1-G\left(x^{*}\right)\right)}{b-a}+f
\end{array}\right.
\end{aligned}
$$

Proposition 1 shows that the pricing band of firm 1 is always higher than that of firm 2, and both firms enjoy positive profits. Note before firm 1 introduces MFS, the firms play a Bertrand game and earn zero profit. Therefore MFS relaxes price competition and benefits all firms.

Corollary 2. Firm 1 has a higher pricing band than firm 2 . Introducing MFS relaxes price competition, resulting higher profits than without MFS.
Proposition 1 shows that the subscribers do not always buy from firm 1 . When the price of firm 2 is low enough $\left(p_{2} \in\left(\frac{\pi_{1}-k\left(1-G\left(x^{*}\right)\right)}{b-a}, \frac{\pi_{2}}{a}\right)\right)$, there is a positive probability that the subscribers buy from firm 2 .

Note the non-subscribers who buy from firm 1 pay $p_{1}+$ $f$, while the subscribers only pay $p_{1}$, who always have lower total purchase costs.

It is easy to verify $\pi_{1}-k\left(1-G\left(x^{*}\right)\right)<\pi_{2}$ for any $a$, which suggests the following result.

Corollary 3. Firm l's profit, before adding the MFS membership fee, is lower than that of firm 2.

\subsection{Stage 2: MFS subscription decision}

Consider the marginal consumer $x^{*}$, who is indifferent between joining MFS or not. If she subscribes to MFS, she needs to pay the membership fee $k$. Her purchase cost depends on from which firm she will purchase from. If $p_{1} \in\left(\frac{\pi_{2}}{a}, \frac{\pi_{1}-k\left(1-G\left(x^{*}\right)\right)}{b-a}+f\right)$, the price difference between two firms is not large, so the consumer will always buy from firm 1. If $p_{1} \in\left(\frac{\pi_{1}-k\left(1-G\left(x^{*}\right)\right)}{b-a}+f, \frac{\pi_{2}}{a}+f\right)$, she will compare $p_{1}$ with $p_{2}+f$ and choose the lower price. Therefore her expected total payout is

$$
\begin{aligned}
& x^{*}\left(\int_{\frac{\pi_{1}-k\left(1-G\left(x^{*}\right)\right)}{b-a}}^{\frac{\pi_{2}}{a}}(p+f) f_{2}^{*}(p)\left(1-F_{1}^{*}(p+f)\right) d p\right. \\
& \int_{\frac{\pi_{2}}{a}}^{\frac{\pi_{1}-k\left(1-G\left(x^{*}\right)\right)}{b-a}+f} p f_{1}^{*}(p) d p+ \\
& \left.\int_{\frac{\pi_{1}-k\left(1-G\left(x^{*}\right)\right)}{b-a}+f}^{\frac{\pi_{2}}{a}+f} p f_{1}^{*}(p)\left(1-F_{2}^{*}(p-f)\right) d p\right)+k .
\end{aligned}
$$

If she does not subscribe to MFS, she always needs to pay the shipping fee $f$ no matter from which firm she purchases, so she always chooses the lower price between the two firms. Her expected total payout is

$$
\begin{aligned}
& x^{*}\left(\int_{\frac{\pi_{1}-k\left(1-G\left(x^{*}\right)\right)}{b-a}}^{\frac{\pi_{2}}{a}}(p+f) f_{2}^{*}(p) d p+\right. \\
& \int_{\frac{\pi_{2}}{a}}^{\frac{\pi_{1}-k\left(1-G\left(x^{*}\right)\right)}{b-a}+f}(p+f)\left(f_{1}^{*}(p)\left(1-F_{2}^{*}(p)\right)+\right. \\
& \left.\left(1-F_{1}^{*}(p) f_{2}^{*}(p)\right) d p\right) .
\end{aligned}
$$

Equating above two equations, we can find the marginal consumer $x^{*}(k)$.

\subsection{Stage 1: membership fee}

Now firm 1 considers how to set an optimal $k$ to maximize its profit. If $k=0$, all consumers will subscribe, so $a=b$. By proposition $1, \pi_{1}=\pi_{2}=0$. If $k$ is too large so that no consumers subscribe, both firms will engage a Bertrand pricing game to attract consumers, and each will 
earn profit zero. Thus an intermediate $k$ yields a higher profit.

Firm 1's problem is

$$
\max _{k} \pi_{1}(k), \text { s. t. } a=\int_{0}^{x^{*}(k)} t g(t) d t
$$

Clearly this problem does not have an analytical solution. We may show the solution with numerical experiments. Assume $x$ follows a uniform distribution, e.g., $\bar{x}=1, g(x)=1$ and $G(x)=x$, and $f=1$. Then $b=\int_{0}^{\bar{x}} t g(t) d t=0.5$ and $a=\frac{x^{* 2}(k)}{2^{2}}$.

By numerical methods, we find the marginal consumer $x^{*}=0.645, a=0.208$ and $k^{*}=0.413$. Note the average number of orders per consumer per year is 0.5 . so 0.413 is about $80 \%$ an average consumer would pay for the yearly total shipping cost. The subscribers are $35.5 \%$ of the total population, and account for about $80 \%$ of total orders.

The firms' profits are $\pi_{1}=0.313$ and $\pi_{2}=0.242$. Firm 1 earns a higher profit than firm 2. The membership fee income is 0.147 , which is about $47 \%$ of firm 1 's total profit. This example shows that if firm 1 sets the membership fee smartly, its total profit could be higher than that of the other firm.

Corollary 4. Firm l's total profit could be higher than that of firm 2, even if its before membership fee-income profit is lower than that of firm 2.

\section{Summary}

In this paper, we are interested in the role membership free shipping plays in affecting competition and how to set the membership fee optimally. We model an asymmetric duopoly with one firm being the pioneer who adopts MFS. Consumers differ in number of orders per year. We show the duopoly will charge different pricing strategies, with the firm with MFS having a higher pricing band than the other firm. Both firms have positive profits. Consumers with higher number of orders per year self-select to subscribe to MFS and always have a lower average total cost per order than other consumers. Despite having to subsidize the subscribers, the MFS firm could still earn a higher profit than the other firm, though the MFS firm's profit excluding membership fees is lower than that of the other firm. The paper also characterizes how to set the optimal membership fee and shows that an intermediate percentage of subscribers is optimal.

This paper provides a basic model that could be extended in multiple ways. Firstly we could consider both firms opt to adopt MFS and competitively set member fees; secondly the model may take into the consideration that non-subscribers may bundle orders to save shipping fees; thirdly search costs may play an important role when subscribers deem the MFS firm the default search starting point.

\section{Appendix}

Proof. Suppose the support of $F_{i}^{*}(p)$ is $P_{i}$ and the upper and the lower bound of $P_{i}$ are $\bar{P}_{i}$ and $P_{i}$. Previously we show $\overline{P_{i}}=P_{i}+f$. By the condition $F_{i}^{*}\left(P_{i}\right)=0$, we find $\underline{P_{1}}=\frac{\pi_{2}}{\alpha}$ and $\underline{P_{2}}=\frac{\pi_{1}-k\left(1-G\left(x^{*}\right)\right)}{b-a}$.

When $P_{1}<p<P_{2}+f$, by the equilibrium condition $\pi_{1}=\Pi_{1}(\bar{p})=(p-\bar{f})(b-a) F_{2}^{*}(p)+(p-f)(b-a)(1-$ $\left.F_{2}^{*}(p)\right)+p a\left(1-F_{2}^{*}(p)\right)+k\left(1-G\left(x^{*}\right)\right)$, so $F_{2}^{*}(p)=$ $\frac{1}{a}\left[b-\frac{\pi_{1}-k\left(1-G\left(x^{*}\right)\right)+f(b-a)}{p}\right]$.

When $P_{2}+f<p<\underline{P_{1}}$, only the subscribers purchase from firm 1. By the equilibrium condition $\pi_{1}=$ $\Pi_{1}(p)=(p-f)(b-a)\left(1-F_{2}^{*}(p-f)\right)+k\left(1-G\left(x^{*}\right)\right)$, so $F_{2}^{*}(p)=\frac{1}{a}\left[b-\frac{\pi_{1}-k\left(1-G\left(x^{*}\right)\right)+f(b-a)}{p}\right]$, and $F_{2}^{*}(p-$ $f)=1-\frac{\pi_{1}-k\left(1-G\left(x^{*}\right)\right)}{(b-a)(p-f)}$. Therefore we have $F_{2}^{*}(p)=$ $1-\frac{\pi_{1}-k\left(1-G\left(x^{*}\right)\right)}{(b-a) p}$ for $\underline{P_{2}}<p<\underline{P_{1}}-f$.

Since $F_{2}^{*}(p)$ is continuous, $F_{2}^{*}\left(\underline{P_{1}}\right)^{-}=F_{2}^{*}\left(\underline{P_{1}}\right)^{+}$, from which we find $\pi_{1}$ as stated in the proposition.

When $P_{1}<p<\underline{P_{2}}+f$, only the non-subscribers purchase from firm 2. By the equilibrium condition $\pi_{2}=$ $\Pi_{2}(p)=p a\left(1-F_{1}^{*}(p)\right)$, so $F_{1}^{*}(p)=1-\frac{\pi_{2}}{a p}$.

When $P_{2}<p<P_{1}$, by the equilibrium condition $\pi_{2}=$ $\Pi_{2}(p)=p \overline{a F_{1}^{*}}(p+f)+p b\left(1-F_{1}^{*}(p+f)\right)$, so $F_{1}^{*}(p+f)=$ $\frac{1}{b-a}\left[b-\frac{\pi_{2}}{p}\right]$. Therefore we have $F_{1}^{*}(p)=\frac{1}{b-a}\left[b-\frac{\pi_{2}}{p-f}\right]$ for $\overline{P_{2}}<p<\overline{P_{1}}$.

Since $F_{1}^{*}(p)$ is continuous, $F_{1}^{*}\left(\overline{P_{2}}\right)^{-}=F_{1}^{*}\left(\overline{P_{2}}\right)^{+}$, from which we find $\pi_{2}$ as stated in the proposition.

\section{References}

Ashley, C., Gillespie, E. A., \& Noble, S. M. (2015). The effect of loyalty program fees on program perceptions and engagement. Journal of Business Research.

Buchanen, J. M. (1953). The theory of monopolistic quantity discounts. Review of Economic Studies, 20(3).

Dolan, R. J. (1987). Quantity discounts: Managerial issues and research opportunities. Marketing Science, 6(1).

Jing, B., \& Wen, Z. (2008). Finitely loyal customers, switchers, and equilibrium price promotion. Journal of Economics \& Management Strategy, 17(3), 683707.

Lewis, M. (2006). The effect of shipping fees on customer acquisition, customer retention, and purchase quantities. Journal of Retailing, 82, 13-23.

Lewis, M., Singh, V., \& Fay, S. (2006). An empirical study of the impact of nonlinear shipping and handling fees on purchase incidence and expenditure decisions. Marketing Science, 25(1), 51-64.

Rogowsky, M. (2014, Feb.). Prime factors: Should amazon really mess with the best loyalty program in retail? Retrieved from http://www.forbes.com/ sites/markrogowsky/2014/02/02/ prime-factors-should-amazon-really -mess-with-the-best-loyalty-program -in-retail/\#22c5893b3381

Rubin, B. F. (2016, January). Your impulse buys are costing amazon a fortune. Retrieved from http: / / 
www. cnet. com/news / your-impulse-buys

-are-costing-amazon-a-fortune/

Tan, X., Ho, Y.-C., \& Tan, Y. (2015, June). Loyalty program: the dilemma of shipping fee. Conference of Information Systems and Technology, Philadelphia.

Tuttle, B. (2011, November). Amazon prime loses \$11 annually per member. and it's a huge success. Retrieved from http://business.time.com/2011/ 11/14/amazon-prime-loses-11-annually -per-member-and-its-a-huge-success/ 